\title{
Age and Growth of Southern Bluefin Tuna, Thunnus maccoyii, Based on Otolith Microstructure
}

\author{
Jeong Eun $\mathrm{Ku}^{1}$ · Sung II Lee ${ }^{1}$ (D) Doo Nam Kim ${ }^{1}$
}

Received: 4 July 2021 / Revised: 24 August 2021 / Accepted: 6 September 2021 / Published online: 27 September 2021

(C) The Author(s) 2021

\begin{abstract}
Age and growth of southern bluefin tuna (SBT, Thunnus maccoyii) were estimated based on otoliths collected by Korean tuna longline vessels in the Atlantic and Indian Oceans from 2015 to 2019. A total of 739 specimens were used to estimate age and growth of SBT, with sizes ranging from 66 to $181 \mathrm{~cm}$ in fork length. It was confirmed that the otolith is a suitable aging characteristic for determining SBT age, and otolith annuli can be used as an annual ring. The relationship between fork length (FL) and total weight $(W)$ was $W=7.7 \mathrm{e}-05 \mathrm{FL}^{2.722}\left(R^{2}=0.874\right)$. The von Bertalanffy's growth parameters estimated from the non-linear method using length-at-age data were $L_{\infty}=170.0 \mathrm{~cm}, K=0.200 /$ year, $t_{0}=-1.615$ years, with $95 \%$ confidence intervals between 166 and $175 \mathrm{~cm}$ for $L_{\infty}, 0.17-0.23$ /year for $K$, and -2.27 to -1.09 years for $t_{0}$ from bootstrapping. The Kimura's likelihood ratio test results of the models under assumptions of common and different parameters between female and male concluded that the growth of SBT has no difference between genders.
\end{abstract}

Keywords Age $\cdot$ Growth $\cdot$ Otolith $\cdot$ Southern bluefin tuna $\cdot$ Thunnus maccoyii

\section{Introduction}

Southern bluefin tuna (SBT, Thunnus maccoyii) are a highly migratory pelagic species found between 30 and $50^{\circ} \mathrm{S}$ latitude in the waters of Southern hemisphere (Harvey et al. 2003). SBT is known to spawn in warm waters south of Java from September to April, and juvenile SBT migrate south down to the west coast of Australia (CCSBT 2018). In addition, by the age of 5, most of SBT have recruited to the adult stock in the open ocean, and at the age of 8-12 after maturation, they migrate between temperate feeding ground and tropical spawning ground (Wang et al. 2009). The diet of juvenile SBT comprises mainly of fish in the continental and shelf waters and squid and planktonic crustaceans in offshore waters (Young et al. 1997; Wilson et al. 2005). In addition, they have the ability to control their body temperature to some extent by reducing heat loss to external circumstance through a highly evolved counter current circulation system (Sharp and Dizon 1977; Brill 1994).

Sung Il Lee

k.sungillee@gmail.com

1 Distant Water Fisheries Resources Research Division, National Institute of Fisheries Science, Busan 46083, Korea
The SBT stock has been exploited by fisheries for over than 50 years (CCSBT 2018), and has been placed on the International Union for Conservation of Nature (IUCN) Red List as Critically Endangered (CR) species from 2009 (Collette et al. 2011). Since then, SBT have been strictly managed by the Commission for the Conservation of Southern Bluefin Tuna (CCSBT), and recently, through the stock rebuilding plan adopted by the Commission which achieves a 0.5 probability of achieving $30 \%$ of the initial total reproductive output (TRO) by 2035, the stock has been showing a signal of increase in the stock (CCSBT 2020).

For the effective management and conservation of SBT, it is crucial to understand the biology of the stock. In addition, several biological parameters are essential for stock assessment. Information on fish age and growth is one of the key parameters required to carry out an accurate stock assessment (Khan and Khan 2014).

Early estimates of SBT age and growth were obtained from length frequency (Serventy 1956) and tag-return data (Shingu 1970). Thorogood (1987) firstly showed the annual SBT age estimates, counting growth zones on whole otoliths, and Gunn et al. (2008) conducted a comprehensive ageing study comparing estimates from otoliths, scales and vertebrae, suggesting that otoliths were the most accurate structures to estimate SBT age over its full length range. 
And Kalish et al. (1996) estimated the absolute age of SBT using bomb radiocarbon chronometry and confirmed that increments in otoliths are formed annually. Based on these evidences, many studies on SBT age and growth have been conducted to develop techniques for preparing and reading otoliths and to standardize the methods for interpreting SBT otoliths, using samples collected by Australian, Japanese, and Indonesian fishing vessels (Shimose and Farley 2016).

Otoliths function to hear and balance the system, and are composed mainly of calcium carbonate and a small amount of organic matrix, both of which are deposited in daily and annual increments as fish grow (Pannella 1980). In addition, otoliths are known to be calcified structures that produce periodic growth increments that are widely used for age determination in fish (Campana 2001). Accurate estimates of age provide key parameters regarding the growth rate of fish as well as other parameters related to population dynamics such as mortality, productivity, and age structure of population (Campana 2001).

The aims of this study are to estimate the von Bertalanffy's growth parameters of SBT using otoliths sampled by Korean tuna longline vessels in the Atlantic and Indian Oceans, and to examine whether there is a difference in growth between female and male. In addition, these results update the growth parameters and the age structure of SBT caught by the Korean fleets and provide useful information for assessing the stock status as well as help to understand SBT biology.

\section{Materials and Methods}

\subsection{Sampling}

Samples of SBT otoliths used in this study were collected by scientific observers of the National Institute of Fisheries Science (NIFS) scientific observer program who were onboard Korea tuna longline vessels in the Atlantic and Indian Oceans from 2015 to 2019 (Fig. 1). Otoliths were sampled in CCSBT statistical area 9 (CCBST 2019) from April to August and in statistical area 8 from August to September (Table 1). A total of 831 SBT specimens were collected, but 739 of them were analyzed in this study, excluding 92 specimens which its gender information wasn't available or the otolith has been damaged. For each specimen, fork length $(\mathrm{FL})$ and total weight $(W)$ were measured to the nearest centimeter $(\mathrm{cm})$ and kilogram $(\mathrm{kg})$, respectively, and gender was determined by inspecting its gonads. The otoliths were extracted by skilled observers, and extraction process is as follows. Otoliths (sagittae) were extracted after removing part of the cranium. After extraction, otoliths were rinsed with water, wiped dry with Kimwipe, and then stored dry

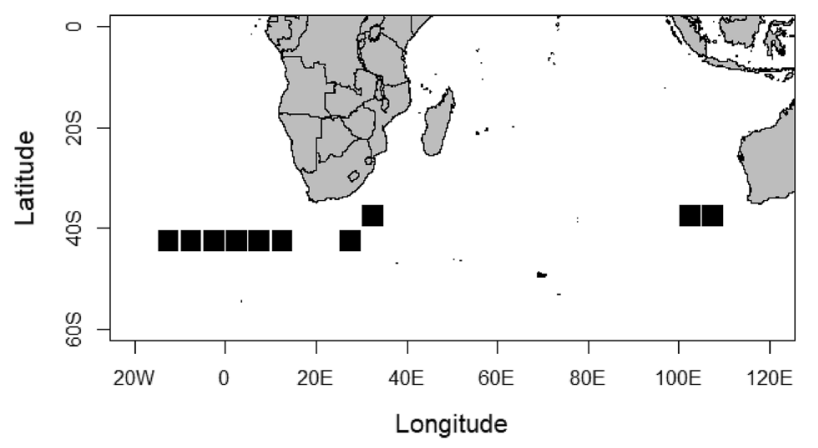

Fig. 1 Map showing sampling areas for estimating the age and growth of southern bluefin tuna (SBT, Thunnus maccoyii), 20152019

in a labeled C.B.C bottle. All the samples were sent to the NIFS for analysis.

\subsection{Otolith Processing}

In the laboratory, each otolith was dried for $24 \mathrm{~h}$ after rinsing with distilled water (Fig. 2), and mounted on the mixture of polyester resin and polyester hardener for $24 \mathrm{~h}$. Otoliths were sectioned using Buehler IsoMet Low Speed Saw. Three serial transverse sections with a thickness of 300-350 $\mu \mathrm{m}$ were made, which usually provided at least one section through the primordium (Fig. 3). Increments were counted under a stereoscopic microscope (SZX-ILLD, Olympus Corporation). When reading SBT otolith, we referred to a manual for age determination of southern bluefin tuna Thunnus maccoyii (CCSBT 2002). Each otolith was read twice by the same reader, and the second reading was done 2 months after the first reading. All readings were made without reference to size, gender, date, sampling location, etc. The boundary from the opaque zone to the translucent zone in the microstructure of the otolith was considered annuli. We measured the distance from the primordium to the edge as otolith radius $(R)$, and the distance from the primordium to each annulus as ring radius $\left(r_{n}\right)$ to the nearest $0.001 \mathrm{~mm}$.

\subsection{Data Analysis}

We analyzed the relationship between the otolith radius and ring radius of each annulus to verify whether the otolith is suitable as the ageing characteristic for determining SBT age and to examine the accuracy of annuli determination.

To examine consistency in replicate readings (precision of readings), the index of average percentage error (APE) (Beamish and Fournier 1981) and coefficient of variation (CV) (Chang 1982) were calculated. 
Table 1 Monthly number of samples, and the range and mean of fork length of southern bluefin tuna (SBT, Thunnus maccoyii) by area, 20152019

\begin{tabular}{|c|c|c|c|c|c|c|c|c|c|}
\hline \multirow[t]{3}{*}{ Month } & \multicolumn{3}{|l|}{ Statistical area 9} & \multicolumn{3}{|l|}{ Statistical area 8} & \multicolumn{3}{|l|}{ Total } \\
\hline & \multirow[t]{2}{*}{ No. of samples } & \multicolumn{2}{|c|}{ Fork length $(\mathrm{cm})$} & \multirow[t]{2}{*}{ No. of samples } & \multicolumn{2}{|c|}{ Fork length $(\mathrm{cm})$} & \multirow[t]{2}{*}{ No. of samples } & \multicolumn{2}{|c|}{ Fork length $(\mathrm{cm})$} \\
\hline & & Range & Mean & & Range & Mean & & Range & Mean \\
\hline 4 & 208 & $100-162$ & 135.9 & & & & 208 & $100-162$ & 135.9 \\
\hline 5 & 152 & $97-174$ & 141.9 & & & & 152 & $97-174$ & 141.9 \\
\hline 6 & 182 & $95-176$ & 134.4 & & & & 182 & $95-176$ & 134.4 \\
\hline 7 & 91 & $107-181$ & 132.3 & & & & 91 & $107-181$ & 132.3 \\
\hline 8 & 8 & $109-127$ & 116.0 & 66 & $66-178$ & 128.2 & 74 & $66-178$ & 126.9 \\
\hline 9 & & & & 32 & $86-168$ & 135.2 & 32 & $86-168$ & 135.2 \\
\hline Total & 641 & $95-181$ & 136.1 & 98 & $66-178$ & 130.5 & 739 & $66-181$ & 135.4 \\
\hline
\end{tabular}

Fig. 2 Photo of whole otolith (sagitta) of SBT of $148 \mathrm{~cm}$ in fork length

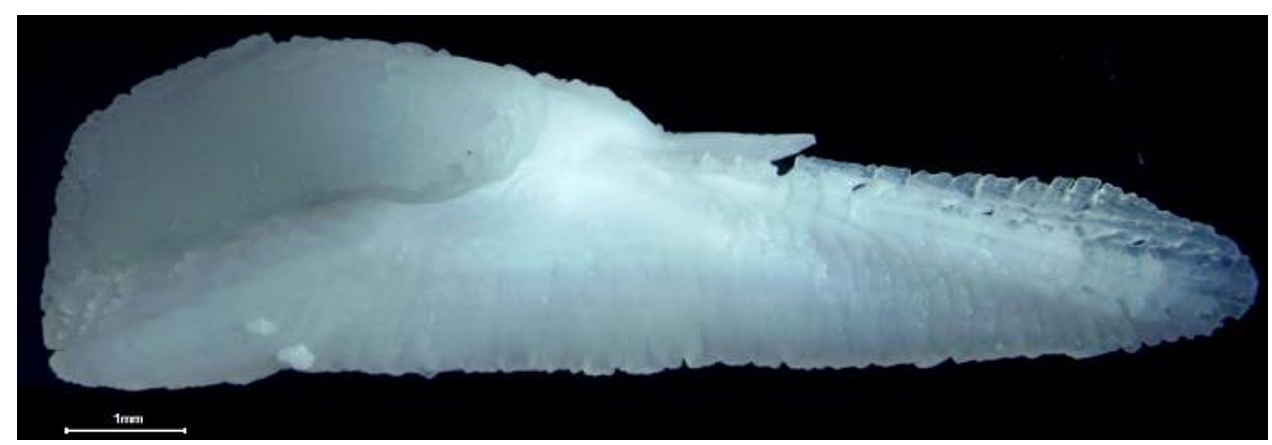

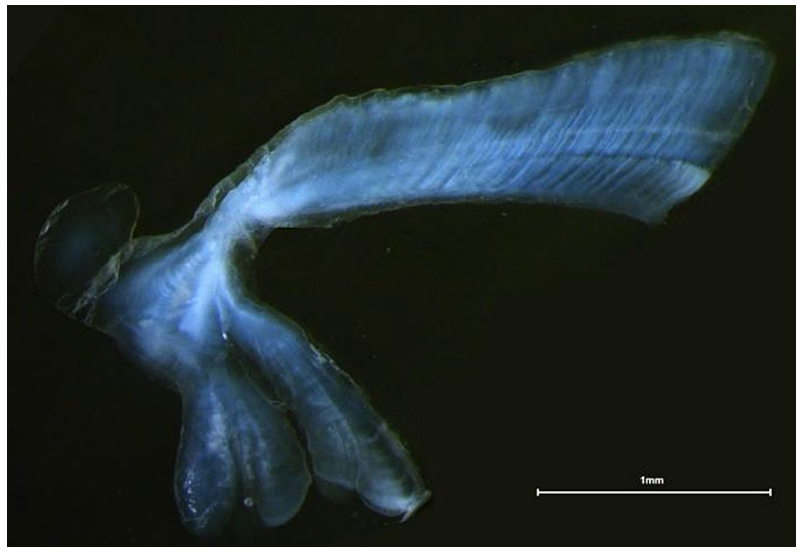

Fig. 3 Photo of transverse sectioned otolith (sagitta) of SBT of $152 \mathrm{~cm}$ in fork length

$\operatorname{APE}_{j}(\%)=100 \times \frac{\sum_{i=1}^{R} \frac{\left|X_{i j}-X_{j}\right|}{X_{j}}}{R}$,

where $R$ is the number of times that each fish was aged, $X_{i j}$ is $i$ th age determination of the $j$ th fish, and $X_{j}$ is the mean age estimate for the $j$ th fish.

The monthly changes in the marginal index (MI) were calculated using the following equation to investigate the formation time of annuli and the annual frequency of the formation.

$\mathrm{MI}=\frac{R-r_{n}}{r_{n}-r_{n-1}}$,

where $R$ is the otolith radius, and $r_{n}$ is the $n$th ring radius.

The relationship between otolith radius $(R)$ and fork length (FL) was estimated,

$\mathrm{FL}=a R+b$,

where $a$ and $b$ are constants, and the mean FL by age at the annuli formation was back-calculated by the equation using the mean ring radius by age.

To determine the relative growth of SBT, we calculated the relationship between fork length (FL) and total weight $(W)$,

$W=a \mathrm{FL}^{b}$,

where $a$ and $b$ are constants. Analysis of variance (ANOVA) was applied to test whether there is a difference in length-weight relationships between genders, which was performed using R software (R Core Team 2018).

We estimated the von Bertalanffy's growth parameters (von Bertalanffy 1957), 
$L_{t}=L_{\infty}\left(1-e^{\left(-K\left(t-t_{0}\right)\right)}\right)$,

where $t$ is age, $L_{t}$ is the length at age $t, L_{\infty}$ is the asymptotic maximum length, $K$ is the growth rate coefficient, and $t_{0}$ is the theoretical age at which the fish would have had zero size. We first calculated the growth parameters using Walford method (Walford 1946) and the mean fork length by age. With the calculated parameters as initial (or starting) values, they were re-estimated by the non-linear method using length-at-age data which consists of length and age estimated to each fish at the time the fish was captured, and their confidence intervals were constructed througth boostrappng with 1000 iterations, using the packages FSA (Ogle et al. 2018) and nlstools (Baty et al. 2015) in the R software. Model fit was examined using the residual plot and histogram, and the scatterplots for the parameters from bootstrapping were plotted to examine the correlation between them. Moreover, we examined whether the von Bertalanffy growth model has an additive error structure or a multiplicative error structure. In addition, to compare the parameters between female and male, we analyzed the non-linear models under different assumptions where SBT had separate parameters for each gender, where there was one parameter in common between genders, and where the parameters were identical for both genders, and conducted Kimura's likelihood ratio test (Kimura 1980) for each model using the package fishmethods (Nelson 2018) in the R software.

\section{Results}

The range of SBT fork length (FL) used for this study was $66-181 \mathrm{~cm}$ and the mean length was $135.4 \mathrm{~cm}$ (Table 1). As for the length distribution by gender, the mean length of female and male were $134.9 \mathrm{~cm}$ and $135.8 \mathrm{~cm}$, respectively, and there was no difference between genders (Fig. 4).

The relationship between the otolith radius and ring radius of each annulus showed that each annulus was clearly distinguishable from the adjacent annulus without an overlap, up to 18 annuli have been observed, and the ring radius increased as the otolith radius increased (Fig. 5). Therefore, otolith is a suitable aging characteristic for determining SBT age, and otolith annuli can be used as an annual ring.

There was no bias detected between age estimates from the initial reading and the second reading, because the values of APE and CV between the two readings were $2.50 \%$ and $6.05 \%$, indicating that the age determination was interpreted consistently.

The monthly changes in the marginal index by age group are shown in Fig. 6, where SBT of 8 years or under were grouped at intervals of 2 or 3 years, and SBT over 9 years were grouped into one group. They ranged from 0.433 to 0.864 , with the value higher in April in age group 2-4 and lower in September in age group 2-4, and showed no significant difference between months and age groups except for age group 2-4 (Fig. 6). The monthly trend for age group 2-4 seemed to be decreased during the period, April-September, but the range of variations was similar to those of other groups (Fig. 6) and the number of samples in some months was not sufficient (Tables 1,2), so it was impossible to make a conclusion from this result alone.
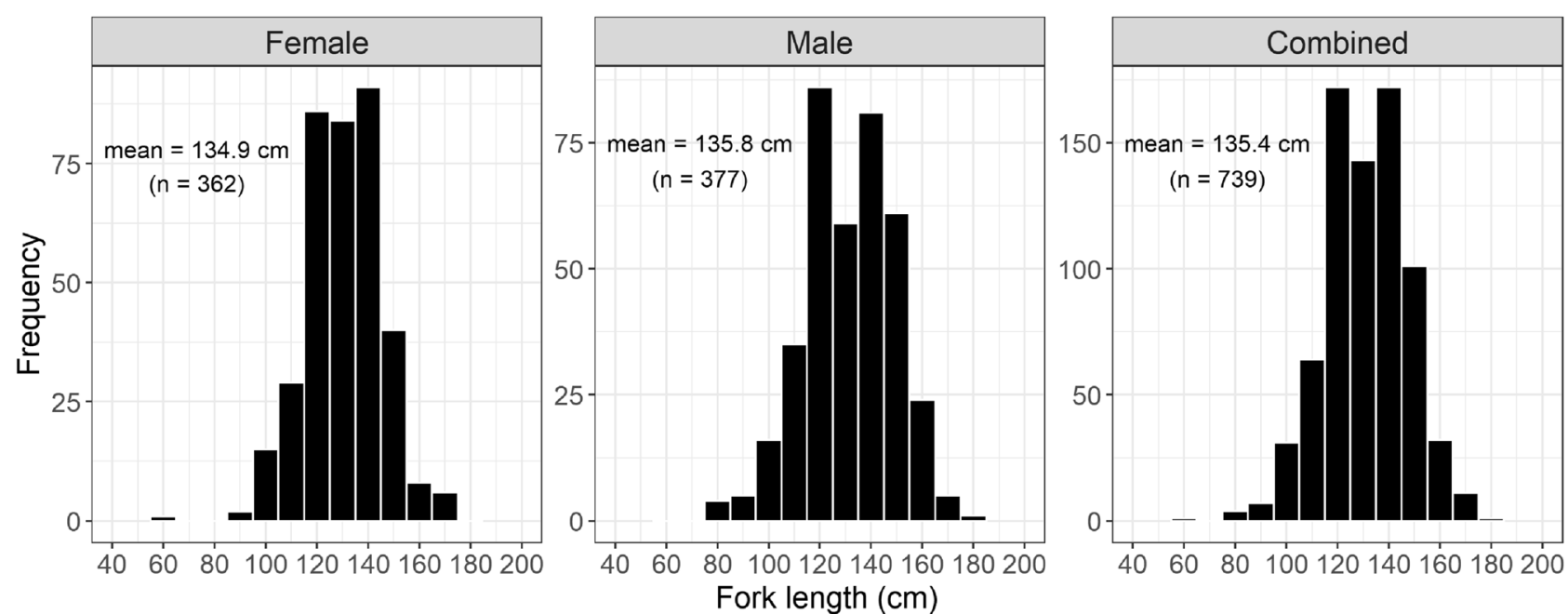

Fig. 4 The length distributions of SBT by gender, sampled in 2015-2019 

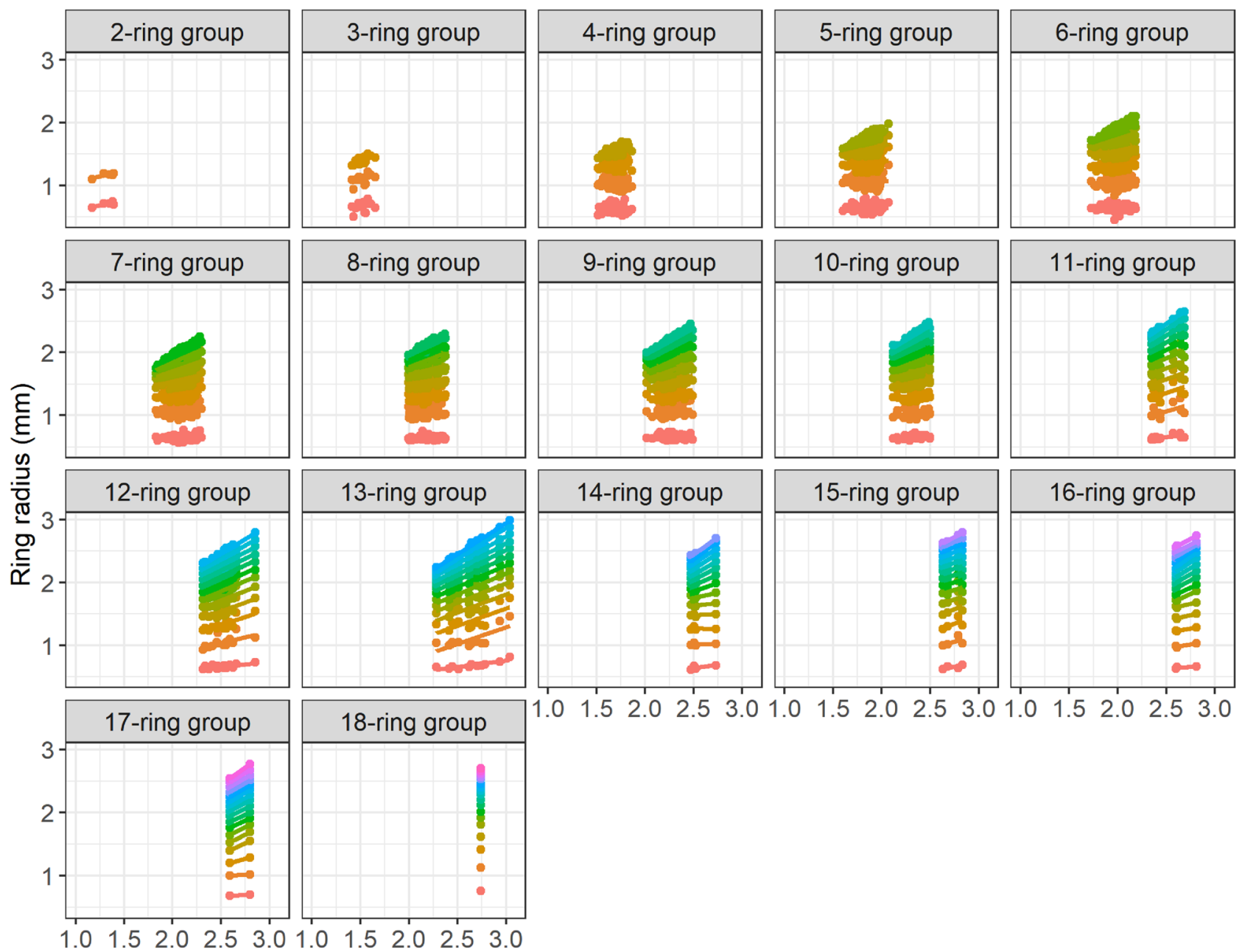

$\begin{array}{lllllllllllllll}1.0 & 1.5 & 2.0 & 2.5 & 3.0 & 1.0 & 1.5 & 2.0 & 2.5 & 3.0 & 1.0 & 1.5 & 2.0 & 2.5 & 3.0\end{array}$

Otolith radius $(\mathrm{mm})$

Fig. 5 The relationship between otolith radius and ring radius of SBT

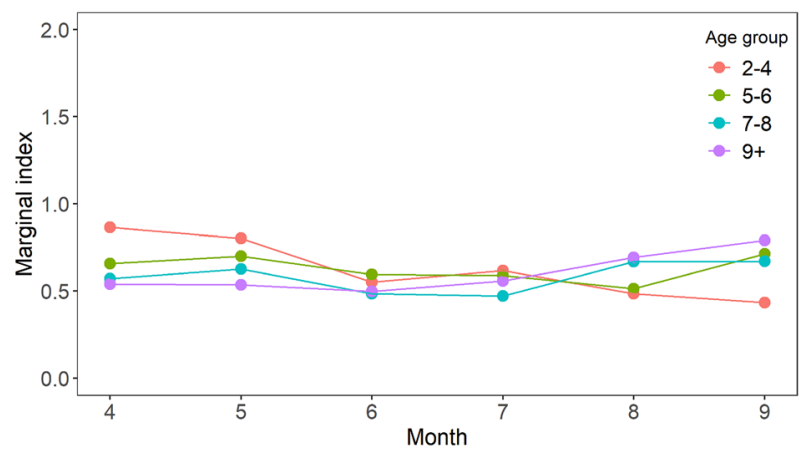

Fig. 6 Monthly changes in the marginal index (MI) of SBT by age group

The mean ring radius on the otolith of SBT ranged from $r_{1}=0.660 \mathrm{~mm}$ to $r_{18}=2.701 \mathrm{~mm}$ (Table 2). Figure 7 shows the relationship between ring radius $(R)$ and fork length (FL), and as the ring radius increased, the fork length increased. Using the mean ring radius (Table 2) and the $R-\mathrm{FL}$ relationship (Fig. 7), the mean fork length for each age was backcalculated from $\mathrm{FL}_{1}=69.3 \mathrm{~cm}$ to $\mathrm{FL}_{18}=166.6 \mathrm{~cm}$ (Table 3 ).

The relationship between fork length (FL) and total weight $(W)$ was $W=7.7 \mathrm{e}-05 \mathrm{FL}^{2.722}\left(R^{2}=0.874\right)$ for gender combined (Fig. 8), and there was no significant difference between genders $(p>0.05)$, indicating that they had statistically equal slopes and intercepts.

With initial values $\left(L_{\infty}=169.2 \mathrm{~cm}, K=0.176 /\right.$ year, $t_{0}=-1.998$ years) estimated by Walford method (1946) using the back-calculated mean fork length, the von Bertalanffy's growth parameters estimated from the non-linear method using length-at-age data were $L_{\infty}=170.0 \mathrm{~cm}$, $K=0.200 /$ year, and $t_{0}=-1.615$ years (Fig. 9). Figure 9 shows the von Bertalanffy growth model for SBT with the 95\% confidence intervals for the mean length-at-age and the $95 \%$ prediction intervals from bootstrapping. All the 


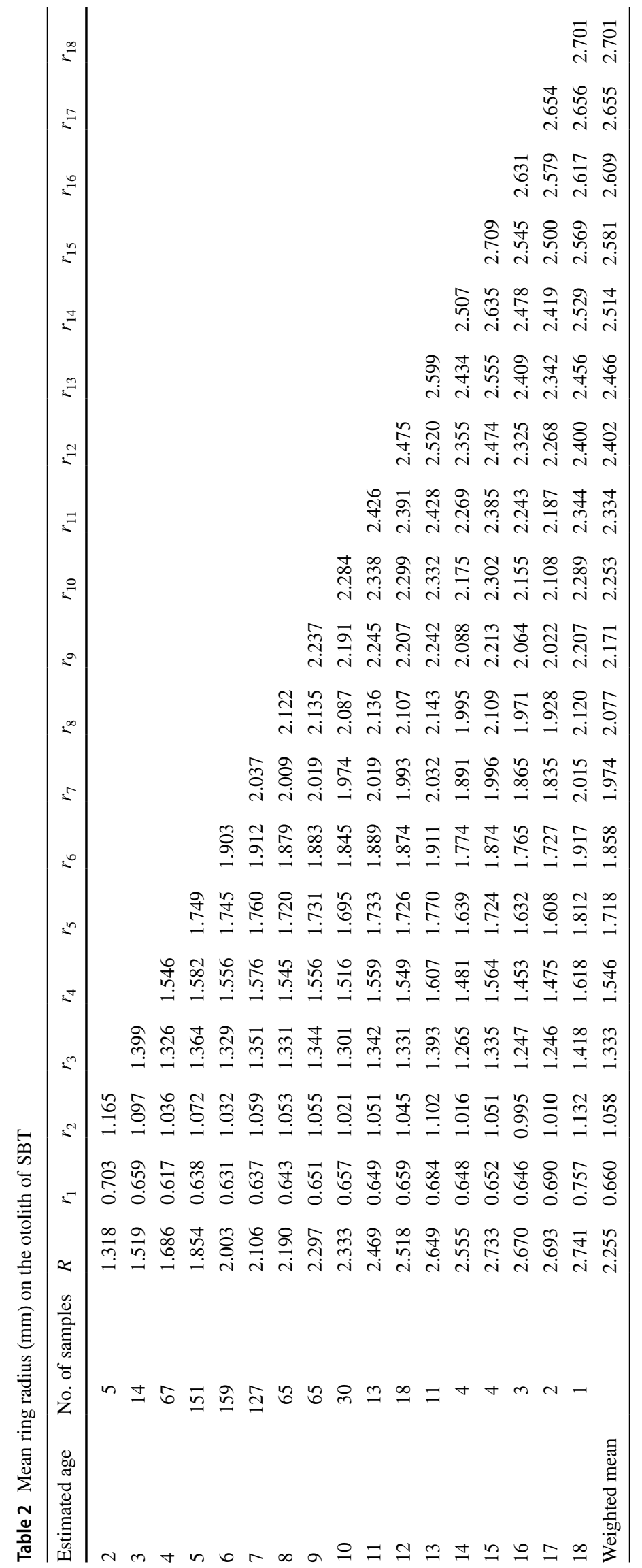




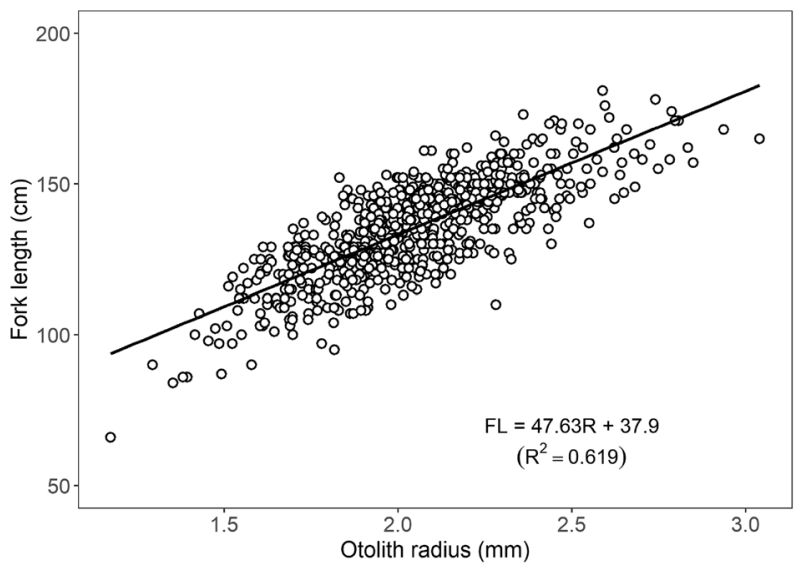

Fig. 7 The relationship between otolith radius $(R)$ and fork length (FL) of SBT

Table 3 Back-calculated fork length for each age of SBT

\begin{tabular}{ll}
\hline Age & Fork length $(\mathrm{cm})$ \\
\hline 1 & 69.3 \\
2 & 88.3 \\
3 & 101.4 \\
4 & 111.5 \\
5 & 119.7 \\
6 & 126.4 \\
7 & 131.9 \\
8 & 136.9 \\
9 & 141.3 \\
10 & 145.2 \\
11 & 149.1 \\
12 & 152.3 \\
13 & 155.3 \\
14 & 157.6 \\
15 & 160.8 \\
16 & 162.2 \\
17 & 164.3 \\
18 & 166.6 \\
\hline
\end{tabular}

parameters from bootstrapping were normally distributed with $95 \%$ confidence intervals between 166 and $175 \mathrm{~cm}$ for $L_{\infty}, 0.17-0.23$ year for $K$, and -2.27 to -1.09 years for $t_{0}$ (Fig. 10), and there was a strong correlation between the paired parameters (Fig. 11). The residual plot from fitting the von Bertalanffy's growth model to the length-at-age data indicates a well-behaved residuals pattern versus fitted values, and the histogram suggests the model has a normal distribution of residuals (Fig. 12a).

For the error structure of SBT growth model, the residual plots showed that the multiplicative error had a slight left-skewed distribution of residuals than the additive error

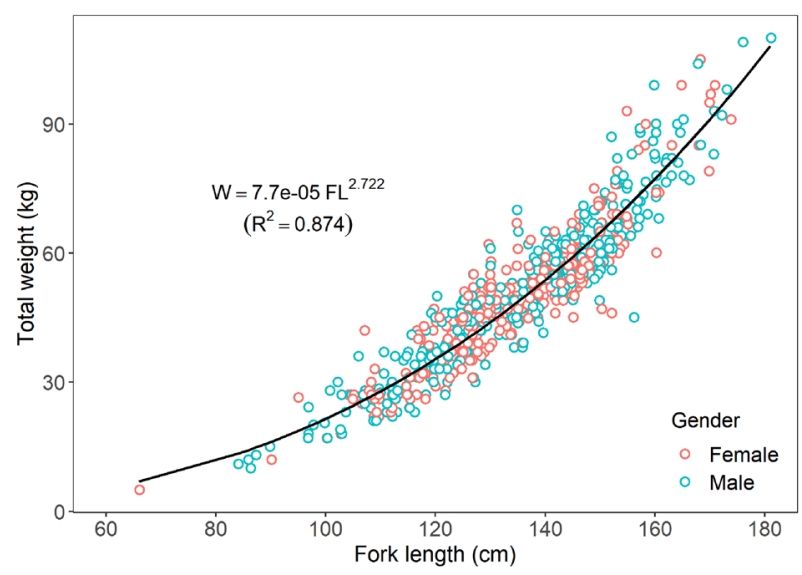

Fig. 8 The relationship between fork length (FL) and total weight (W) of SBT combined genders

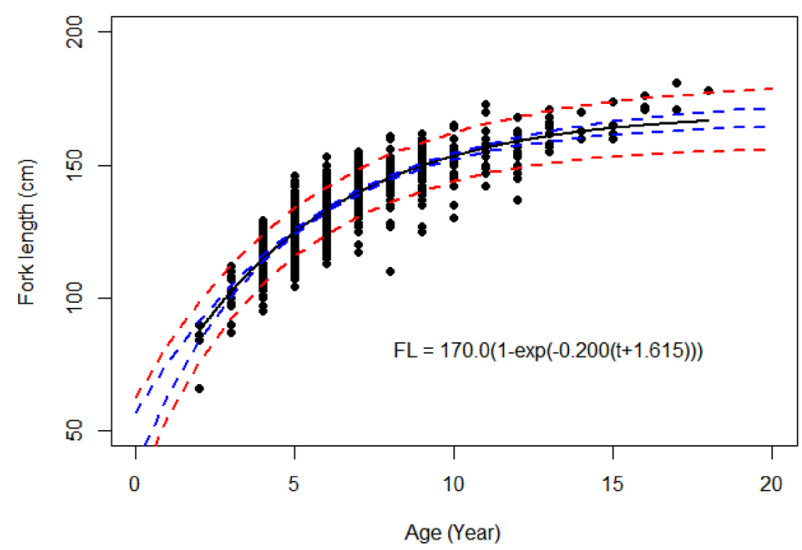

Fig. 9 The von Bertalanffiy's growth curve for SBT. Red and blue dotted lines represent $95 \%$ bootstrap confidence interval and 95\% bootstrap prediction interval, respectively

structure (Fig. 12). Therefore, the additive structure error model was chosen to represent the SBT growth parameters.

Table 4 shows the Kimura's likelihood ratio test results of the models under different assumptions where SBT had separate parameters for each gender $\left(\mathrm{H}_{0}\right)$, where there was one parameter in common between genders $\left(\mathrm{H}_{1}, \mathrm{H}_{2}, \mathrm{H}_{3}\right)$, and where the parameters were identical for both genders $\left(\mathrm{H}_{4}\right)$. These results indicated that the growth of SBT has no significant difference between genders $(p>0.05)$.

\section{Discussion}

The von Bertalanffy's growth parameters of SBT estimated from the non-linear method were $L_{\infty}=170.0 \mathrm{~cm}, K=0.200 /$ year, and $t_{0}=-1.615$ years, and there was no difference 

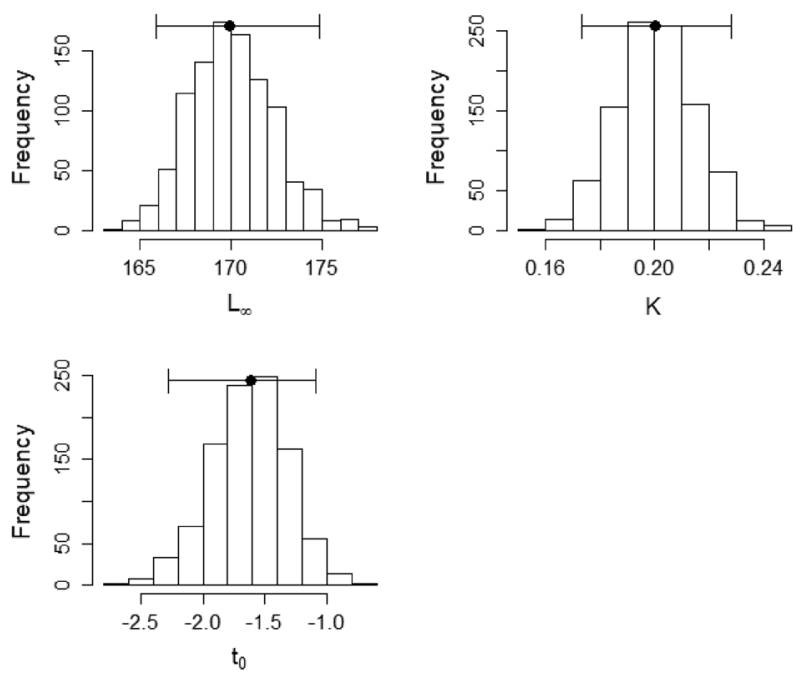

Fig. 10 Histograms of the bootstrap results for the von Bertalanffy's growth parameters for SBT. The horizontal line in each graph indicates $95 \%$ bootstrap confidence interval
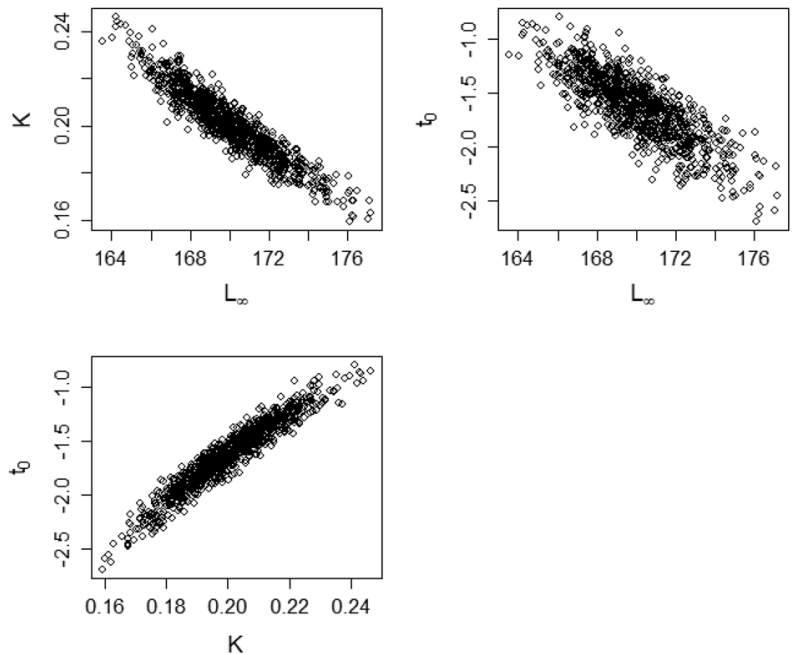

Fig. 11 Paired scatterplots for the parameters of bootstrap results for the von Bertalanffy's growth model for SBT

between female and male (Kimura's likelihood ratio test, $p>0.05$ ).

Since 1899 back-calculation method has been applied to reconstruct growth patterns of fish with otoliths, bones, and scales (Jones 1992). This approach is used to infer or back-calculate size at ages prior to capture, using measurements made on these bony structures (Vigliola and Meekan 2009). It is known that back-calculation has been used to generate fish growth history as an invaluable tool. However, this approach can cause a problem where the back-calculated length differs significantly from the observed length (Francis 2006). For the reasons, in this
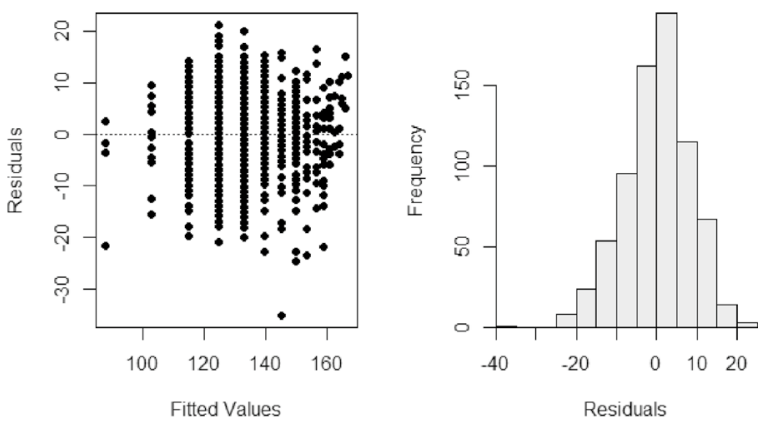

(a) Additive error structure
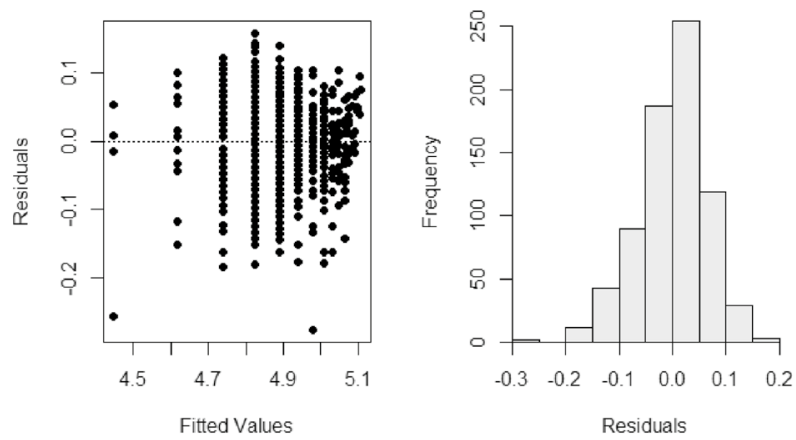

(b) Multiplicative error structure

Fig. 12 Residual plots and residual histograms from fitting the von Bertalanffy's growth model to SBT length-at-age data under assumptions where the model had the additive error structure or the multiplicative error structure

Table 4 Kimura's likelihood ratio test results of the models under different assumptions of growth parameters between female and male

\begin{tabular}{lllll}
\hline Tests & Hypothesis & df & Chi-squared test & $p$ values \\
\hline $\mathrm{H}_{0}$ vs $\mathrm{H}_{1}$ & $L_{\infty} 1=L_{\infty} 2$ & 1 & 0.18 & 0.617 \\
$\mathrm{H}_{0}$ vs H $_{2}$ & $K 1=K 2$ & 1 & 0.05 & 0.823 \\
$\mathrm{H}_{0}$ vs H $_{3}$ & $t_{0} 1=t_{0} 2$ & 1 & 0.43 & 0.512 \\
$\mathrm{H}_{0}$ vs H $_{4}$ & $L_{\infty} 1=L_{\infty} 2$, & 3 & 4.09 & 0.252 \\
& $K 1=K 2$, & & & \\
& $t_{0} 1=t_{0} 2$ & & & \\
\hline
\end{tabular}

study, back-calculation was performed using the relationship between ring radius and fork length to calculate the mean length-at-age, but these mean lengths were used to estimate the initial values to be applied to the non-linear method. The choice of initial values is important to the non-linear regression algorithms, because inappropriate values can cause the problem to not converge to a minimum residual sum of squares (RSS), to behave erratically or not at all, or to find a local minimum RSS rather than the global best fit minimum value (Motulsky and Ransnas 1987). Length-at-age data, instead of the mean length data, were used for estimating the growth parameter so that it 
Table 5 Comparison of the von Bertalanffy's growth parameters for SBT estimated in this study with those of previous studies

\begin{tabular}{lllllll}
\hline Reference & \multicolumn{2}{l}{ Parameters } & \multicolumn{2}{l}{$\begin{array}{l}\text { Aging char- } \\
\text { acteristics }\end{array}$} & Age (years) & Range of FL (cm) \\
\cline { 2 - 4 } & $L_{\infty}$ & $K$ & $t_{0}$ & & \\
\hline This study & 170.0 & 0.200 & -1.615 & Otolith & $2-18$ & $66-181$ \\
Gunn et al. (2008) & 183.2 & 0.185 & -0.923 & Otolith & $1-41$ & $26-216$ \\
Thorogood (1987) & 261.3 & 0.108 & -0.157 & Otolith & Mostly $<6$ & $42-167$ \\
Yukinawa (1970) & 219.7 & 0.135 & -0.040 & Scale & $<8$ & $38-184$ \\
\hline
\end{tabular}

could get the information about individual variability at age.

Determination of age and growth is very important in ichthyological investigations as fish growth is one of the main parameters that can determine the stock status (Mikhailov and Prodanov 1983). We compared the von Bertalanffy's growth parameters estimated in this study with the previously reported values (Table 5). There were some differences in the parameters between the studies, but the results of Gunn et al. (2008) were analogous to this study except for the difference observed in $L_{\infty}$. It is believed that such difference comes from the fact that the maximum length of the samples used in Gunn et al. (2008) was $216 \mathrm{~cm}$ at the age of 41 while that used in this study was $181 \mathrm{~cm}$ at the age of 18 . In addition, given the differences in length-at-age, there is a difference in the length of age 1. On contrary to studies on juvenile SBT (Yukinawa 1970; Thorogood 1987; Itoh and Tsuji 1996), which reported the length at age 1 at $28-50 \mathrm{~cm}$, Farley et al. (2007) and this study estimated the mean length at age 1 at $82-89 \mathrm{~cm}$ and $69 \mathrm{~cm}$, respectively. There is a need to investigate why such difference occurs between the estimated length of age 1 by each method. There would be the differences between otolith processing methods and its interpretation. Accurate estimation of growth parameters is vital for stock assessments and management of exploited species (Fujinami et al. 2019). Mendoza (2006) also noted that accurate size-at-age and age-at-first maturity estimations are highly important for conservation and management of exploitable fishery resources.

In terms of precision analysis, APE and CV have been widely used as measures of age precision in ageing studies (Andrade et al. 2019). However, there is no criterion which can be used to decide the precision for ageing studies, because the precision is highly influenced not only by the age reader but also by the species and the nature of the structure (Campana 2001). Although there are no reference points for the precision for fish, based on literatures for fish aging studies, Campana (2001) suggested the values of $\mathrm{APE}=5.5 \%$ and $\mathrm{CV}=7.6 \%$ as the reference points. Values of both precision ( $\mathrm{APE}=2.50 \%, \mathrm{CV}=6.05 \%$ ) for $\mathrm{SBT}$ aging carried out in this paper were lower than those reference points, indicating the assigned ages are acceptably precise.

However, there are studies that need to be further investigated in the future. First, younger fish under the age of 2 and older fish over the age of 14 should be supplemented to obtain more accurate growth parameters for SBT. Since recently Korean tuna longline vessels fishing for SBT start fishing in April and end in November due to their SBT quota (Lee et al. 2020), there is a limit to the year-round sampling of SBT by the vessels. Therefore, estimating the age and growth of SBT will require a joint research with countries or organizations interested in the study. Second, fish age is typically determined based on its biological birthday with monthly changes in marginal index (MI). However, as the monthly changes in MI of SBT shown in this study did not show a significant trend and its spawning season is too long from September to April (CCSBT 2018), the age and growth of SBT were analyzed using the estimated length-at-age data. Recently, Proctor et al. (2021) introduced how to determine age using the assigned birthday and the marginal state of the otolith. That is, if the spawning season is unknown, or fish spawn year-round, January 1 st can be used as the assigned birthday in the northern hemisphere and July 1st in the southern hemisphere (Morales-Nin 1992). This approach can place fish that are spawned in the same cohort into the correct year-class or age-class (Proctor et al. 2021). In the future, we would like to use the approach to analyze the age and growth of SBT and compare the differences between the two methods.

Fish growth rates can be changed by exploitation, which should be monitored periodically, particularly for the over-exploited fish. Therefore, the results of this study are expected to provide useful information to better understand the recent changes in the growth of SBT and to assess and manage the stock status.

Acknowledgements The authors thank all the people who helped publish this paper. This study was supported by a grant from the National Institute of Fisheries Science (R2021029).

Open Access This article is licensed under a Creative Commons Attribution 4.0 International License, which permits use, sharing, adaptation, distribution and reproduction in any medium or format, as long as you give appropriate credit to the original author(s) and the source, provide a link to the Creative Commons licence, and indicate if changes were made. The images or other third party material in this article are included in the article's Creative Commons licence, unless indicated otherwise in a credit line to the material. If material is not included in the article's Creative Commons licence and your intended use is not permitted by statutory regulation or exceeds the permitted use, you will 
need to obtain permission directly from the copyright holder. To view a copy of this licence, visit http://creativecommons.org/licenses/by/4.0/.

\section{References}

Andrade I, Rosa D, Muñoz-Lechuga R, Coelho R (2019) Age and growth of the blue shark (Prionace glauca) in the Indian Ocean. Fish Res 211:238-246. https://doi.org/10.1016/j.fishres.2018.11. 019

Baty F, Ritz C, Charles S, Brutsche M, Flandrois JP, Delignette-Muller ML (2015) A toolbox for nonlinear regression in R: the package nlstools. J Stat Softw 66(5):1-21. http://www.jstatsoft.org/v66/ i05/

Beamish RJ, Fournier DA (1981) A method for comparing the precision of a set of age determinations. Can J Fish Aquat Sci 38(8):982-983. https://doi.org/10.1139/f81-132

Brill RW (1994) A review of temperature and oxygen tolerance studies of tunas pertinent to fisheries oceanography, movement models and stock assessment. Fish Oceanogr 3(3):204-216. https://doi. org/10.1111/j.1365-2419.1994.tb00098.x

Campana SE (2001) Accuracy, precision and quality control in age determination, including a review of the use and abuse of age validation methods. J Fish Biol 59(2):197-242. https://doi.org/ 10.1111/j.1095-8649.2001.tb00127.x

CCSBT (2002) A manual for age determination of southern bluefin tuna Thunnus maccoyii. Report of the Direct Age Estimation Workshop, CCSBT. https://www.ccsbt.org/sites/default/files/userf iles/file/docs_english/meetings/meeting_reports/ccsbt_09/report of_daews.pdf. Accessed 1 Oct 2002

CCSBT (2018) Report on biology, stock status and management of southern bluefin tuna: 2018. Report of the Twenty Third Meeting of the Scientific Committee, CCSBT. https://www.ccsbt.org/sites/ default/files/userfiles/file/docs_english/meetings/meeting_reports/ ccsbt_25/report_of_SC23.pdf. Accessed 1 Oct 2018

CCSBT (2019) Resolution on the implementation of a CCSBT catch documentation scheme. CCSBT. https://www.ccsbt.org/sites/ ccsbt.org/files/userfiles/file/docs_english/operational_resolutions/ Resolution_CDS.pdf. Accessed 1 Oct 2019

CCSBT (2020) Report of the twenty fifth meeting of the scientific committee. CCSBT. https://www.ccsbt.org/sites/default/files/userfiles/ file/docs_english/meetings/meeting_reports/ccsbt_27/report_of_ SC25.pdf. Accessed 1 Oct 2020

Chang WY (1982) A statistical method for evaluating the reproducibility of age determination. Can J Fish Aquat Sci 39(8):1208-1210. https://doi.org/10.1139/f82-158

Collette B, Chang S-K, Di Natale A, Fox W, Juan Jorda M, Miyabe N, Wang S (2011) Thunnus maccoyii. The IUCN red list of threatened species. https://doi.org/10.2305/IUCN.UK.2011-2.RLTS. T21858A9328286.en. Accessed 2 Apr 2019

Farley JH, Davis TL, Gunn JS, Clear NP, Preece AL (2007) Demographic patterns of southern bluefin tuna, Thunnus maccoyii, as inferred from direct age data. Fish Res 83:151-161. https://doi. org/10.1016/j.fishres.2006.09.006

Francis RICC (2006) Back-calculation of fish length: a critical review. J Fish Biol 36(6):883-902. https://doi.org/10.1111/j.1095-8649. 1990.tb05636.x

Fujinami Y, Semba Y, Tanaka S (2019) Age determination and growth of the blue shark (Prionace glauca) in the western North Pacific Ocean. Fish Bull 117(1):107-120. https://doi.org/10.7755/FB. 117.1-2.12

Gunn JS, Clear NP, Carter TI, Rees AJ, Stanley CA, Farley JH, Kalish JM (2008) Age and growth in southern bluefin tuna, Thunnus maccoyii (Castelnau): direct estimation from otoliths, scales and vertebrae. Fish Res 92:207-220. https://doi.org/10.1016/j.fishres. 2008.01.018

Harvey E, Cappo M, Shortis M, Robson S, Buchanan J, Speare P (2003) The accuracy and precision of underwater measurements of length and maximum body depth of southern bluefin tuna (Thunnus maccoyii) with a stereo-video camera system. Fish Res 63(3):315-326. https://doi.org/10.1016/S0165-7836(03)00080-8

Itoh T, Tsuji S (1996) Age and growth of juvenile southern bluefin tuna Thunnus maccoyii based on otolith microstructure. Fish Sci 62(6):892-896. https://doi.org/10.2331/fishsci.62.892

Jones CM (1992) Development and application of the otolith increment technique. In: Stevenson DK, Campana SE (eds) Otolith microstructure examination and analysis. Department of Supply and Services, Ottawa, pp 1-11

Kalish JM, Johnston JM, Gunn JS, Clear NP (1996) Use of the bomb radiocarbon chronometer to determine age of southern bluefin tuna Thunnus maccoyii. Mar Ecol Prog Ser 143:1-8. https://doi. org/10.3354/meps 143001

Khan S, Khan MA (2014) Importance of age and growth studies in fisheries management. In: Proceedings of national seminar on next generation sciences: vision 2020 and beyond, Marharshi Dayanand University, Rohtak, 8 Mar 2014

Kimura D (1980) Likelihood methods for the von Bertalanffy growth curve. Fish Bull 77:765-776

Lee SI, Lim JH, Lee MK, Kwon Y (2020) 2020 Annual National Report of Korean SBT Fishery. CCSBT https://www.ccsbt.org/en/ system/files/ESC25_SBT\%20Fisheries_KR_rev1.pdf. Accessed 1 Oct 2020

Mendoza RPR (2006) Otoliths and their applications in fishery science. Ribarstvo 64(3):89-102

Mikhailov K, Prodanov K (1983) Approximate assessment of the natural mortality coefficient in the Black Sea anchovy. Proc IFR Varna 20:173-182

Morales-Nin B (1992) Determination of growth in bony fishes from otolith microstructure. FAO, Rome, FAO Fisheries Technical Paper 322, p 51

Motulsky HJ, Ransnas LA (1987) Fitting curves to data using nonlinear regression: a practical and nonmathematical review. FASEB J 1:365-374

Nelson GA (2018) Fishmethods: fishery science methods and models. $\mathrm{R}$ package version 1.11-0. https://CRAN.R-project.org/package= fishmethods. Accessed 20 Nov 2018

Ogle DH, Wheeler P, Dinno A (2018) FSA: fisheries stock analysis $\mathrm{R}$ package version 0.8.22. https://github.com/droglenc/FSA. Accessed 22 Nov 2018

Pannella G (1980) Growth patterns in fish sagittae. In: Rhoads DC, Lutz RA (eds) Skeletal growth of aquatic organisms. Plenum Press, New York, pp 519-560

Proctor C, Robertson S, Jatmiko I, Clear N (2021) An introductory manual to fish ageing using otoliths. Fish aging services Pty Ltd, Hobart, p 41

R Core Team (2018) R: a language and environment for statistical computing. R Foundation for Statistical Computing, Vienna. https:// www.r-project.org/. Accessed 2 Jul 2018

Serventy DL (1956) The southern bluefin tuna, Thunnus thynnus maccoyii (Castelnau), in Australian Waters. Mar Freshw Res 7:1-43. https://doi.org/10.1071/mf9560001

Sharp GD, Dizon AE (1977) The physiological ecology of tunas. New York Academic Press, New York, p 485

Shimose T, Farley JH (2016) Age, growth and reproductive biology of bluefin tunas. In: Kitagawa T, Kimura S (eds) Biology and ecology of bluefin tuna. CRC Press, London, pp 47-77

Shingu C (1970) Studies relevant to distribution and migration of the southern bluefin tuna. Bull Far Sea Fish Res Lab 3:57-113 
Thorogood J (1987) Age and growth rate determination of southern bluefin tuna, Thunnus maccoyii, using otolith banding. J Fish Biol 30(1):7-14

Vigliola L, Meekan MG (2009) The back-calculation of fish growth from otoliths. In: Green BS, Mapstone BD, Carlos G, Begg GA (eds) Tropical fish otoliths: information for assessment, management and ecology. Springer, Dordrecht, pp 174-211. https://doi. org/10.1007/978-1-4020-5775-5_6

von Bertalanffy L (1957) Quantitative laws in metabolism and growth. Q Rev Biol 32(3):217-231

Walford LA (1946) A new graphic method of describing the growth of animals. Biol Bull 90:141-147

Wang CH, Lin YT, Shiao JC, You CF, Tzeng WN (2009) Spatiotemporal variation in the elemental compositions of otoliths of southern bluefin tuna Thunnus maccoyii in the Indian Ocean and its ecological implication. J Fish Biol 75(6):1173-1193. https:// doi.org/10.1111/j.1095-8649.2009.02336.x

Wilson SG, Lutcavage ME, Brill RW, Genovese MP, Cooper AB, Everly AW (2005) Movements of bluefin tuna (Thunnus thynnus) in the northwestern Atlantic Ocean recorded by pop-up satellite archival tags. Mar Biol 146(2):409-423. https://doi.org/10.1007/ s00227-004-1445-0

Young JW, Lamb TD, Le D, Bradford RW, Whitelaw AW (1997) Feeding ecology and interannual variations in diet of southern bluefin tuna, Thunnus maccoyii, in relation to coastal and oceanic waters off eastern Tasmania, Australia. Environ Biol Fish 50(3):275-291

Yukinawa M (1970) Age and growth of southern bluefin tuna Thunnus maccoyii (CASTELNAU) by use of scale. Bull Far Sea Fish Res Lab 3:229-257

Publisher's Note Springer Nature remains neutral with regard to jurisdictional claims in published maps and institutional affiliations. 